\title{
Thomas Edison Speculates on the Uses of the Phonograph
}

\author{
By Rebecca P. Butler
}

$\mathbf{0}$

n December 24, 1877, Thomas Edison filed a patent for a new medium - the phonograph. Invented while working on a way to record telephone conversations, Edison would eventually produce a number of phonographs, including the cylinder, concert, disc, and school phonographs. (Paralejas, 2006) In 1878, Edison speculated on a number of possible uses for his new invention:

1. Letter writing and all kinds of dictation without the aid of a stenographer.

2. Phonographic books, which will speak to blind people without effort on their part.

3. The teaching of elocution.

4. Reproduction of music.

5. The "Family Record"--a registry of sayings, reminiscences, etc., by members of a family in their own voices, and of the last words of dying persons.

6. Music-boxes and toys.

7. Clocks that should announce in articulate speech the time for going home, going to meals, etc.

8. The preservation of languages by exact reproduction of the manner of pronouncing.

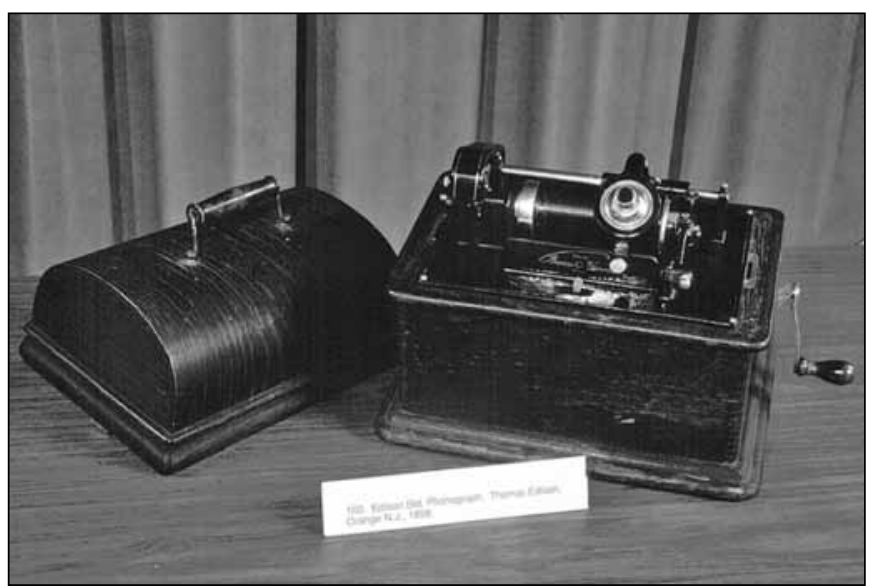

Edison's Standard Phonograph. Lee and Lida Cochran AECT Archives. Blackwell Museum of Education. Northern Illinois University, 1999

9. Educational purposes; such as preserving the explanantions made by a teacher, so that the pupil can refer to them at any moment, and spelling or other lessons placed upon the phonograph for convenience in committing to memory.

10. Connection with the telephone, so as to make that instrument an auxiliary in the transmission of permanent and invaluable records, instead of being the recipient of momentary and fleeting communication. (Library of Congress, 1999, 1)

Given the above, one can see examples of realities that came out of this "accidental invention": technological innovation in one area creating innovation in another.

\section{References}

Lee and Lida Cochran AECT Archives. (1999). Edison standard phonograph. DeKalb, Illinois: Blackwell Museum of Education, Northern Illinois University. Available: http://www.cedu.niu.edu/ blackwell/multimedia/images/JPEGS/ SLIDE160.JPG

Library of Congress (1999). The History of the Edison cylinder phonograph. Available: http://memory.loc.gov/ammem/edhtml/ edcyldr.html

Paralejas, C.G. (2006). AECT archives' project: Edison standard phonograph. DeKalb, Illinois: ETT 640, Northern Illinois University. 